\title{
Microwave-assisted pretreatment of sago palm bark
}

\begin{abstract}
Three types of microwave-assisted diluted solvents were employed using $0.1 \mathrm{~N} \mathrm{H} 2 \mathrm{SO} 4$ (MSA), $0.1 \mathrm{~N} \mathrm{NaOH}(\mathrm{MSH})$, and $0.01 \mathrm{~N} \mathrm{NaHCO} 3$ (MSB). These solvents were evaluated as possible pretreatment routes for sago palm bark (SPB) with their effects on the pretreated substrate. A variety of analyses, consisting of fiber analysis, energy dispersive X-ray spectroscopy (EDX), $\mathrm{X}$-ray fluorescence spectrometer (XRF), X-ray powder diffraction (XRD), thermogravimetric analysis (TGA), scanning electron microscope (SEM), and high-performance liquid chromatography (HPLC), were performed to understand the pretreatment effects on the chemical and physical characteristics of SPB and pretreatment liquor. The thermal analysis has revealed that higher hemicellulose degradation was also found in MSA pretreatment. In the analyses of the pretreatment liquid for the extracted monomeric sugar, a higher amount of glucose was found $(9 \mathrm{mg} / \mathrm{g}$ ) using MSH pretreatment and the highest xylose level was found (4 mg/g) using MSA pretreatment. The analysis of the formation of inhibitors has shown that acetic acid was only found in the MSH pretreatment.
\end{abstract}

Keyword: Pretreatment; Microwave; Sago palm bark; Monomeric sugar; Inhibitors 